\title{
O CONSUMO CULTURAL DE JOVENS NA CULTURA
} HALLYU*

Aline Gomes Santana**, Salett Tauk Santos***

* Recebido em: 20.11.2018. Aprovado em: 15.12.2018.

** Mestre em Consumo, Cotidiano e Desenvolvimento Social pela Universidade Federal Rural de Pernambuco/UFRPE. Email: alinev7_@hotmail.com

*** Professora Titular da Universidade Federal Rural de Pernambuco. Docente do Programa de Pós-Graduação em Extensão Rural e Desenvolvimento Local (Posmex/UFRPE) e do Programa de Pós Graduação em Consumo, Cotidiano e Desenvolvimento Socia (PGDCS-UFRPE) Email: mstauk@hotmail.com
Resumo: O artigo investiga o processo de hibridização cultural vivenciado por jovens universitários no consumo da cultura de origem sul-coreana denominado hallyu. A perspectiva teórica correlaciona a teoria de hibridização discutida por García Canclini com as ideias de Bauman sobre modernidade e o perfil da juventude contemporânea proposto por Martín-Barbero. A partir da observação do comportamento dos jovens em suas interações sociais no campo real e virtual, e suas manifestações de consumo, buscamos compreender por que estes indivíduos, ancorados nas tecnologias da informação e comunicação - TICs, buscam referências na hallyu para reconverter suas práticas culturais orientando suas identidades. A abordagem metodológica utiliza, além de pesquisa bibliográfica, técnicas de observação direta, entrevista semiestruturada e a netnografia para coletar informações nos sites e redes sociais, visto ser a internet um espaço de interação privilegiado pelos indivíduos observados.

Palavras chave: Juventude; Hibridização Cultural; Hallyu; Consumo; Identidade.
Abstract: The article investigates the process of cultural hybridization experienced by young academics in the cultural consumption of South Korean origin called Korean wave. The theoretical perspective correlates the hybridization theory discussed by García Canclini, with Bauman's ideas about modernity; and the profile of the contemporary youth proposed by Martín-Barbero. From observation of the behaviour of young people in their social interactions in the real and virtual field and its manifestations, we seek to understand why these individuals, anchored in the information and communication technologies - ICT, seek references the Korean wave, to reconvert their cultural practices guiding their identities. The methodological approach uses, in addition to abibliographical research, techniques for direct observation, semistructured interview and netnography to collect information on the websites and social networks, since it is the internet a privileged interaction space by individuals observed.

Key-words: Youth; Cultural Hybridization; Korean Wave; Consumption; Identity. 


\section{Introdução}

O objetivo deste estudo é analisar o processo de construção identitária de jovens universitários do Recife a partir da interação com o segmento cultural estrangeiro sul-coreano denominado hallyu. $\mathrm{O}$ artigo trata de um recorte de uma pesquisa maior feita com jovens consumidores da hallyu, usuários ativos da internet residentes na cidade do Recife. Pretende-se discutir por que estes jovens tendem a se apropriar da hallyu, utilizando o consumo dos elementos característicos desta cultura como norteador de sua formação identitária enquanto atores sociais no contexto onde estão inseridos. Busca-se compreender por que os jovens escolhem a hallyu como referência para reconverter sua cultura de origem numa cultura estrangeira tão distante no que se refere às condutas e ao espaço geográfico.

Para estar inserido em uma determinada sociedade, o indivíduo precisa se definir como ser social, a partir da determinação de suas escolhas e opiniões. Segundo Cuche (1999), é através da sua identidade social que o sujeito definirá sua posição e se enquadrará nos grupos que the pareçam atrativos e convenientes, a partir da sua identificação com os membros que compõem estes grupos. Essa identidade social é construída através das interações sociais, por intermédio das relações que o indivíduo tende a construir, e pela seleção de elementos socioculturais feitos por este sujeito ao observar e interagir com o meio social. De acordo com o autor:

$$
\begin{aligned}
& \text { A identidade de um indivíduo se caracteriza pelo } \\
& \text { conjunto de suas vinculações em um sistema } \\
& \text { social: vinculado a classe sexual, a uma classe } \\
& \text { de idade, a uma classe social, a uma nação etc. A } \\
& \text { identidade permite que o indivíduo se localize } \\
& \text { em um sistema social e seja localizado } \\
& \text { socialmente (CUCHE, 1999, p. 177). }
\end{aligned}
$$

Nesse sentido, para formular a sua identidade, o ator social busca referências em outros sujeitos e grupos com os quais se identifica. Alguns sujeitos buscam tais referências, principalmente, por não possuir forma simbólica para manifestar-se como ser social e dizer quem são, por isso tomam outras pessoas e grupos como orientadores de suas características e atitudes comportamentais.

$\mathrm{Na}$ sociedade existem inúmeros indivíduos e grupos que procuram referências para formular e manifestar sua identidade, a fim de serem percebidos e se destacarem por tais características. Entre os muitos sujeitos estão os jovens que vivenciam o processo de transição etária determinante para a formação de sua identidade.

Com uma visão de mundo diferente das gerações que a antecedem, a juventude moderna é percebida por sua perspectiva social baseada em valores, condutas, interesses e necessidades divergentes da sociedade que a cerca. Orientada pelo dinamismo do século XXI, estes jovens tendem a aplicar em suas práticas cotidianas o conceito de imediatismo, vivenciando uma constante transição em suas escolhas, as quais direcionam sua formação 
identitária. Conforme Bauman (2011), esta geração caracteriza-se pela fluidez com que constrói suas relações, as quais são comumente formadas e/ou mantidas com o auxílio das tecnologias digitais, utilizadas pelos jovens como principal ferramenta de comunicação e manifestação social.

De acordo com Martín-Barbero (2008), por estar inserida em processos sociais transitórios, esta geração jovem apresenta um novo olhar para a vida, a partir de uma leitura de mundo mais ampla e diversificada, orientada principalmente pelo uso das tecnologias da informação e comunicação - TICs.

Ancorados nos meios digitais para interagir com o mundo, os jovens são bombardeados de informações a todo instante. A cada novo click, estes indivíduos descobrem um universo vasto de conteúdos variados, oriundos das mais diversas fontes sociais e culturais. E, através deste ciberespaço, a juventude consegue captar e difundir conteúdos, além de receber o feedback de tais propagações, principalmente com o uso das redes sociais. Estas redes virtuais funcionam como segmentador social, ao possibilitar a estes jovens localizar e selecionar indivíduos que apresentam características socioculturais semelhantes à sua, proporcionando a formação de grupos sociais que podem permanecer no campo virtual ou materializar-se no campo real. E tais grupos acabam influenciando as práticas cotidianas destes jovens, orientando a sua identidade social.

Dossiê Consumo e Subjetividade

Arquivos do CMD, Volume7, N.2. Ago/Dez 2018
Os jovens se apresentam geralmente em grupos com gostos e comportamentos semelhantes. De acordo com Cuche (1999), cada sujeito alimenta-se de características diferentes que contribuem para sua identificação social, podendo ser, dentre as muitas, a de classe sexual, social e/ou de idade.

Na juventude, o sujeito busca referências para construir sua identidade, e o grupo social no qual se insere contribui para essa construção. Neste processo de formação, os jovens tendem a buscar estereótipos que lhes sirvam como modelo, para que possam formular o seu eu social, o qual busca se comportar de forma a atender às demandas dos indivíduos ao seu redor. A escolha por tal grupo ocorre a partir das características comuns de seus membros. O tipo de vocabulário, as vestimentas, os interesses e tudo mais que expresse a cultura de determinado grupo são elementos segmentadores destas tribos constituintes do universo jovem.

Entre os muitos elementos que orientam a formatação da identidade na juventude, a cultura é um dos mais fortes na segmentação dos grupos de referência, pois nesta fase busca-se uma distinção quanto aos demais indivíduos, e a aderência a culturas diferentes permite uma maior proximidade deste objetivo. Para Zalis (2016), o indivíduo vivencia uma movimentação dentro do ambiente social, afastando-se de sua cultura de origem e aproximando-se de culturas distintas da sua, a fim de sentir-se pertencente a algo dentro do contexto social. Esta sensação de deslocamento se justifica, conforme o autor, pela ausência de 
representação percebida pelos indivíduos, provocada pela velocidade das mudanças tecnológicas e sociais do mundo contemporâneo - um mundo no qual predomina a diversidade cultural e as hibridizações resultantes das interações entre os povos, possibilitadas pela mobilidade comunicacional oriunda do uso das TICs. Neste cenário, os jovens recebem influências de diferentes culturas, favorecidos pela facilidade que ostentam em utilizar as novas tecnologias. Entre as diferentes culturas das quais os jovens se apropriam e utilizam como orientação de suas identidades, está a cultura sul-coreana conhecida como hallyu.

Conforme Kim (2009), hallyu significa “onda coreana”, e refere-se ao movimento de difusão da cultura sul-coreana por outros territórios além do seu. Sua difusão mundial teve início por volta de 1990, tendo chegado ao Brasil em meados de 2002, graças à divulgação feita por fãs brasileiros através da internet e das mídias sociais de vídeos de K-pop (música pop coreana).

Tal segmento cultural tem tomado um espaço cada vez maior entre os jovens de diferentes regiões do Brasil, onde ocorrem eventos e grande manifestação da onda coreana, conquistando mais adeptos ao consumo de seus elementos, e inserção destes em suas práticas cotidianas.

Esta interação e apropriação cultural ocorre embasada principalmente pelo uso das TICs, visto ser a internet o meio preferido pelos jovens para o consumo informações e referências de forma imediata, independente de distâncias culturais e geográficas.
Partindo das discussões apresentadas por Martín-Barbero (2008) e Bauman (2001, 2011), a busca por posicionar-se na sociedade desperta nos jovens a demanda por uma necessidade constante de referências sociais. Entre as muitas opções de referência, a hallyu tem sido escolhida por alguns jovens brasileiros para consumo e formação identitária. Tal interação destes jovens com a hallyu desencadeia um processo de hibridização, pois o contato entre estas culturas distintas (a brasileira e a sul-coreana) leva o jovem a vivenciar uma reconversão cultural, na medida em que busca adaptar a hallyu à sua cultura de origem, inserindo em seu cotidiano elementos característicos da cultura oriental.

Quando se fala em hibridização, faz-se necessário trazer ao diálogo as abordagens apresentadas por Néstor Garcia Canclini, responsável por difundir esta temática na América Latina. Para o autor, o termo hibridização define melhor as interações ocorridas entre culturas diferentes. Com a intensificação da globalização, povos distintos têm se aproximado e interagido com mais frequência, possibilitando o contato entre suas culturas, contribuindo para os processos de hibridização cultural. Para Canclini (2013), novas modalidades de cultura surgem a partir do cruzamento intercultural, que ocorre nas mais diversas formas envolvendo o culto, o popular e o massivo. Pode-se perceber o hibridismo como a mediação entre culturas a partir do processo de ruptura de fronteiras existente entre estas, percebido por Canclini (2013) ao afirmar que tais relações permitem que as culturas percam 
a relação exclusiva com o seu território, mas ganhem em comunicação e conhecimento. Burke (2006) corrobora com tal abordagem ao afirmar que vivemos em uma era de encontros e trocas culturais. Tais mesclas possibilitam o surgimento de novas culturas e/ou a manutenção das já existentes, através de sua reconversão ao adaptá-las às construções apresentadas pelos indivíduos, a partir das informações que recebem no cenário no qual estão inseridos e envolvidos de alguma forma.

À medida que os jovens se apropriam de características da cultura hallyu, incorporando-as às suas práticas cotidianas, eles vivenciam um processo de reconversão cultural. Esse hibridismo cultural desencadeia algumas mudanças no comportamento destes jovens, que, influenciados pela cultura oriental, reformulam suas práticas cotidianas. Tais mudanças repercutem na sociedade que tenta adaptar-se aos novos interesses dessa juventude, seja na aceitação de sua postura estética e comportamental, seja na adequação do mercado aos seus novos interesses de consumo.

Nessa direção a pesquisa analisa por que estes jovens buscam em uma cultura aparentemente tão distante no que se refere à conduta e à posição territorial, orientação para formular sua identidade, e como se manifesta esta hibridização cultural em suas práticas cotidianas. Além disso, o estudo possibilita compreender como esta geração interage utilizando os meios virtuais e de que forma tal interação interfere em seu cotidiano.
Percebe-se a importância desta pesquisa visto que tais indivíduos tendem a vivenciar um processo de hibridização com a cultura da Coreia do Sul, influenciando diretamente em suas práticas cotidianas e em sua interação social.

Tendo em vista o crescimento de adeptos da hallyu, principalmente entre os jovens, percebe-se a necessidade de um estudo sobre tal fenômeno e, sendo mínima a existência de material que discuta sobre o mesmo, esta pesquisa anseia proporcionar mais conhecimentos sobre o tema, bem como sobre o comportamento dos jovens na contemporaneidade, a partir de um campo de visão diferente dos já existentes.

\section{A pesquisa}

Como percurso teórico-metodológico para a construção da presente pesquisa, foi utilizada a perspectiva dos estudos culturais, elegendo o processo de hibridização cultural como orientador da construção identitária dos indivíduos, a partir das interações culturais, auxiliadas principalmente pelas TICs. O campo de observação da temática em questão é a cidade do Recife, sendo a população em estudo os jovens universitários moradores do Recife, com faixa etária entre 17 e 29 anos, adeptos à cultura hallyu.

Além da análise de material bibliográfico, foi utilizada a observação direta, por ser considerada, segundo Moreira (2002, p. 52), "uma estratégia de campo que combina ao mesmo tempo a 
participação ativa com os sujeitos, a observação intensiva em ambientes naturais, entrevistas abertas informais e análise documental".

Foram utilizadas, igualmente, técnicas etnográficas de coleta de dados para análise dos fenômenos percebidos no processo de reconversão cultural e formação identitária, fortalecendo a ideia do autor ao afirmar que "o modo de vida peculiar que caracteriza um grupo é entendido como a sua cultura. Estudar a cultura envolve um exame dos comportamentos, costumes e crenças aprendidos e compartilhados do grupo" (ANGROSINO, 2009, p. 16). Desse modo, o uso das técnicas etnográficas contribui para uma melhor compreensão quanto à análise das manifestações culturais praticadas pelos jovens a partir de sua reconversão à cultura hallyu.

A análise do conteúdo virtual foi realizada utilizando a técnica da netnografia, que consiste, segundo Kozinets (2010), numa opção de pesquisa etnográfica na forma online, isto é, no campo virtual dos conteúdos publicados nas comunidades virtuais, em seus diferentes locais - fóruns, sites, blogs, redes sociais. A netnografia foi fundamental para auxiliar na compreensão sobre o que é e como se difunde a cultura hallyu, por haver pouco material bibliográfico que apresentasse informações sobre a mesma.

Também foi realizada a aplicação de roteiro de entrevista, estruturada em blocos, sendo o primeiro para identificação do entrevistado; o segundo para percepção da sua visão sobre seu cotidiano e sua cultura de origem; o terceiro bloco para verificação sobre seu conhecimento relativo à cultura hallyu; e o quarto bloco para análise das apropriações da cultura hallyu pelos jovens em estudo. Os entrevistados estão identificados por nomes escolhidos pelos próprios jovens durante a realização das entrevistas, para que seja possível preservar suas identidades.

Os dados coletados foram distribuídos em categorias para melhor visualização sobre a forma como os jovens reconvertem os códigos da sua cultura nos elementos da cultura hallyu. Assim foram utilizadas as seguintes categorias de análise: K-drama, Kmovie, Programas de TV, K-beauty e K-pop.

\section{O Consumo cultural como ponto de partida}

As muitas possibilidades trazidas pela modernidade digital cria nos indivíduos novas expectativas quanto às relações e possibilidades sociais e principalmente sobre suas práticas de consumo. Cria-se um anseio por uma sociedade mais igualitária na qual todos têm vez, sem distinção, e os padrões sociais e estéticos são atingidos por todos, e o consumo se dá sem limites. Estas formulações sobre a vida social leva os jovens a dirigir seu cotidiano de forma mais próxima a alcançar tais projeções. Para isto, se apropriam de culturas que enxergam como correlatas às expectativas (muitas vezes utópicas) que formulam.

Frente a este anseio dos jovens por conquistar tais padrões sociais, a indústria cultural se aproveita para produzir elementos que 


\section{Aline Gomes Santana}

Salett Tauk Santos

atraiam este público propondo, a partir de estratégias de marketing manifestas pelas mídias, o alcance de tais expectativas. Neste contexto de consumo, a hallyu surge como uma destas indústrias culturais que busca comercializar bens e ideologias a partir da propagação de uma cultura, voltada a atrair o público jovem.

\section{Hallyu: um negócio da Coreia}

A difusão da cultura hallyu para o mundo teve início através das mídias com a disseminação, em sites e canais abertos da internet, de dramas coreanos e vem se expandindo com a divulgação dos mais diversos elementos presentes em seu cotidiano. Com uma cultura bastante rica, composta por uma variedade de elementos, de acordo com Kim (2009), a cultura sul-coreana tem alcançado um grande espaço no mercado mundial e a hallyu tem contribuído para esta difusão.

Além disso, a hallyu tem contribuído para o crescimento econômico do país, com suas produções culturais, alcançando mais adeptos que tendem a consumi-las com frequência. Nesse sentido a hallyu surgiu como um segmento cultural formulado com o intuito de propagar a Coreia do Sul, aproveitando a oportunidade para movimentar o mercado do país, estimulando o consumo de produtos da sua cultura. A hallyu pode ser percebida como um mecanismo da indústria cultural sul-coreana que cresce cada vez mais não só na
Coreia do Sul, mas em diferentes regiões do mundo, a exemplo da Europa, América do Norte e América latina.

De acordo com a matéria publicada no site The Korea Times (S/D), os fãs da hallyu já ultrapassaram o quantitativo de 35 milhões em 86 países, sendo a Ásia e a Oceania detentoras do maior número de fãs, com 26,20 milhões, seguida pela América com 7,58 milhões, Europa com 1.630.000 e África e o Oriente Médio com uma média de 170.000 seguidores.

Na América Latina o Brasil aparece como um dos países que abriram as portas para a hallyu recebendo artistas e também produzindo eventos ligados ao movimento. Utilizando principalmente as mídias digitais, a onda coreana tem conseguido atravessar o oceano e alcançado o Brasil com suas produções em diferentes segmentos, como: o K-drama, o K-movie, produções de entretenimento para TV e o K-pop, além dos conteúdos produzidos para as redes digitais, constituindo a internet a principal ferramenta de disseminação e consumo da hallyu.

É interessante observar que, nesse movimento para atrair os jovens de outros contextos à cultura hallyu, vão-se assimilando elementos que trazem relação com a realidade deste público, e esta interação faz com que a onda coreana adquira um caráter híbrido, na medida em que combina as características da cultura asiática com elementos de outras culturas, como os da norte-americana e da cultura latina, como pode ser observado na figura abaixo. 


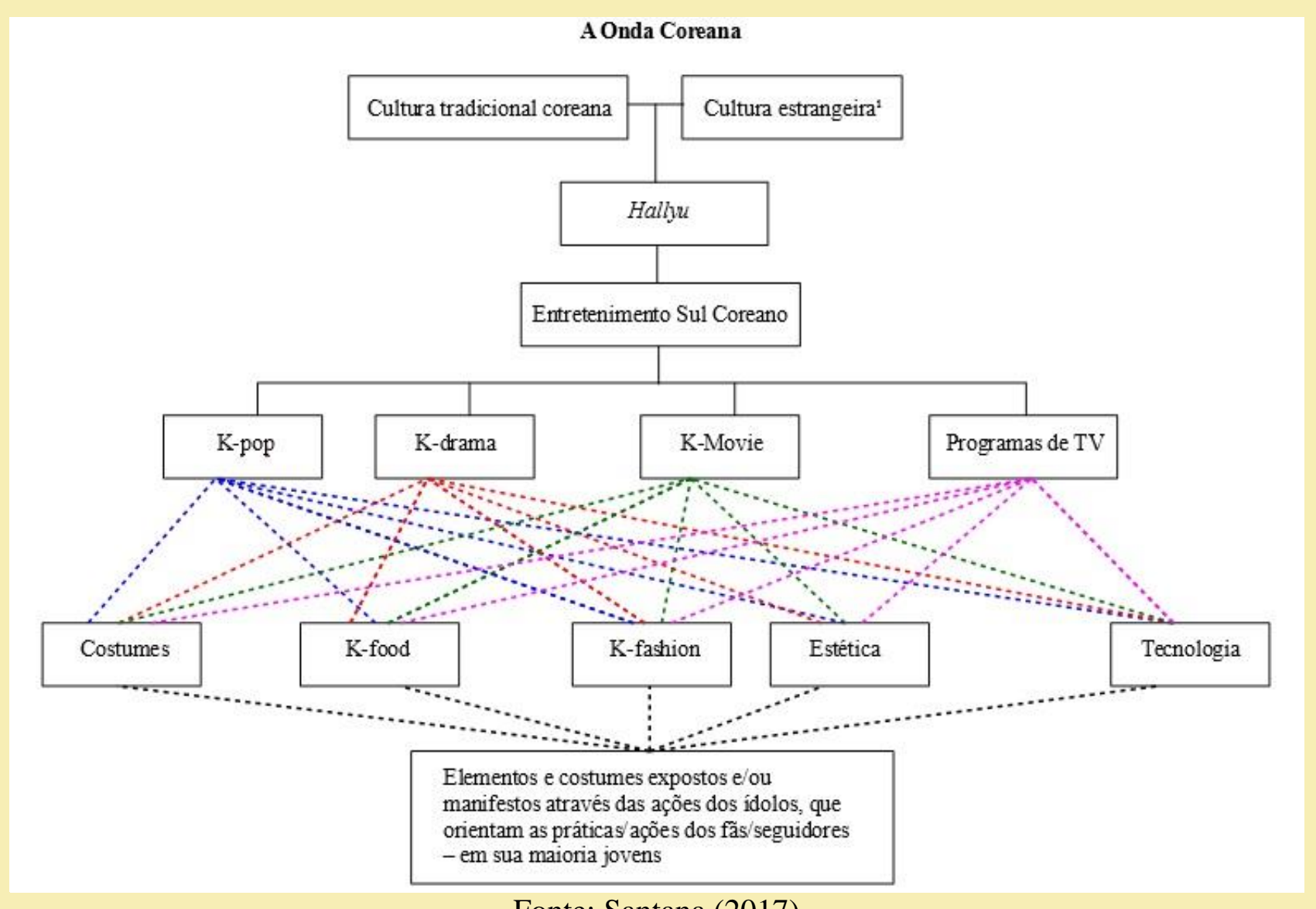

Fonte: Santana (2017)

\section{Os elementos da hallyu}

K-drama - novelas ou séries coreanas

A hallyu começou a se propagar através de suas produções de entretenimento em 2003, com o lançamento da série da produtora KBS, Winter Sonata (Sonata de Inverno), transmitida pela emissora sul-coreana NHK. A novela tornou-se um sucesso absoluto, o que contribuiu para a propagação da hallyu não somente no território asiático, mas também em outras partes do mundo. Com o passar do tempo, mais pessoas começaram a consumir as telenovelas e séries produzidas pela Coreia do Sul e hoje estas são difundidas em diferentes países, através de sites responsáveis por comercializar os chamados K-dramas ou doramas em diferentes idiomas. 


\section{Aline Gomes Santana}

\section{Salett Tauk Santos}

\section{K-movie}

Além das novelas, a Coreia do Sul também se popularizou mundialmente com suas produções cinematográficas. De acordo com Kim (2009), foi a partir de 1961 que os filmes coreanos passaram a ser consumidos pelo mundo e também a receber prêmios importantes como os do Festival de Berlim em 1961, 1994, 2004 e 2007 e os do Festival Cannes em 2002, 2004 e 2007.

Difundindo-se pelo Ocidente, as produções de cinema hallyu têm cada vez mais adentrado o mercado brasileiro com obras como Memórias de um assassino (2003), A irmandade da guerra (2004) e mais recentemente o filme de terror Invasão Zumbi, lançado em 2016, e que recebeu críticas positivas de sites como Omelete, Adorocinema e Veja.com por atrair mais de 100.000 de espectadores para as salas dos cinemas do Brasil.

\section{K-pop}

Pode-se afirmar que o K-pop seja o principal difusor da hallyu. Atraindo principalmente o público jovem, a música pop sulcoreana tem alcançado cada vez mais as paradas de sucessos mundiais e quebrado recordes ao superar principalmente cantores do cenário musical norte-americano.

O k-pop conquista mais fãs ao apresentar produções visuais em seus clipes musicais de alta qualidade, além de megaeventos realizados na Coreia do Sul e em outros países. A busca pela excelência vocal proporciona a exposição de artistas com alta qualidade vocal somada a apresentações coreográficas impecáveis, atraindo uma multidão de fãs devotados a estes ídolos. E, de acordo com Kim (apud Jake Lee, 2009, p 158), “o K-pop encontrou a fórmula certa para conectar audiências na Ásia, ditar tendências e fazer música pop. Essa indústria está crescendo sem precedentes, mais do que qualquer outra cena de entretenimento da Ásia”.

De fato, o K-pop tem difundido a hallyu pelo mundo, conquistando seguidores em diferentes países, e no Brasil é possível perceber cada vez mais o crescimento de adeptos a este estilo musical, que teve sua ascensão com o sucesso Gangnam Style, do cantor Psy em 2012. Após o cantor, outros artistas conquistaram os fãs brasileiros, principalmente os grupos como Big Bang, BTS, K.A.R.D., Twice, entre tantos outros conhecidos principalmente pelos jovens brasileiros.

Os programas de TV sul-coreanos têm ultrapassado as fronteiras e alcançado mais telespectadores pelo mundo. É possível encontrar sites e páginas criadas por fãs que divulgam as produções sul-coreanas com legendas em diferentes idiomas buscando atender a demanda do público bastante diversificado. Programas como Weekly Idol, Knowing Brother, The return of superman são algumas das muitas produções sul-coreanas que, logo após a transmissão, têm seus episódios traduzidos rapidamente e disponibilizados nas diferentes plataformas para os espectadores localizados fora da Coreia do Sul. 


\section{K-beauty}

Diante do crescimento da hallyu, as empresas de cosméticos da Coreia do Sul perceberam nos seguidores da onda coreana um público potencial para direcionar seus produtos. Já é possível encontrar na indústria estética cosméticos relacionados a hallyu, por serem ligados a k-dramas, ou principalmente a idols da cultura em questão.

\section{Os jovens e a cultura hallyu}

A onda coreana atrai diferentes perfis de seguidores, sendo a maioria jovens. Os jovens brasileiros consumidores da onda coreana apresentam características bastante diversificadas, seja pela localização, pela classe social, pelo gênero, formação acadêmica e as demais características que tipificam e segmentam os jovens no Brasil.

Entre estes muitos grupos juvenis, temos os jovens da Cidade do Recife que têm percebido na hallyu uma opção de coletar informações para alimentar sua identidade social.

\section{Perfil dos jovens entrevistados}

Compreender como se dá o consumo da hallyu pelos jovens do Recife exigiu que buscássemos jovens universitários entre 18 e 29 anos, procedentes da cidade do Recife e que consumissem a hallyu em suas múltiplas manifestações através das produções midiáticas e/ou da aquisição de bens oriundos/correlatos dessa cultura.

Os jovens entrevistados são estudantes de instituições de ensino superior, públicas e privadas do Recife, sendo estes pertencentes a diferentes níveis econômicos. Pontuamos aqui que não foram analisados os parâmetros referentes a classe social/econômica dos entrevistados, visto não parecer este contexto relevante para alcançar os objetivos pretendidos pela pesquisa neste momento.

Parte desses jovens realizam alguma atividade remunerada, enquanto outros apenas estudam. A maioria dos jovens contatados ainda reside com seus pais, não possuem completa independência financeira, contando ainda com o auxílio de seus parentes para sua manutenção.

Parte dos jovens afirmou não possuir nenhuma crença religiosa, e os que possuem a praticam por influência de seus pais. E estes jovens afirmaram ainda não participar de nenhum movimento político-social. É relevante salientar estes dois pontos (religião e política), pois os jovens, em sua maioria, não demonstraram ter nenhuma base onde fixem sua fé/confiança, na perspectiva religiosa, não manifestando crença em nenhum ser superior. É interessante citar o depoimento de um dos entrevistados, pois este pontuou haver relação entre sua crença e o consumo de um dos elementos a hallyu: Eu acho até que a minha religião me influenciou
a gostar um pouco de k-pop e a cultura hallyu,
porque... é.... quando você tem uma criação
cristã, você tende a abominar coisas 


\begin{abstract}
pecaminosas e coisas que sejam muito chulas, aquela exposição carnal e aquela cultura meio, digamos assim, safada (ar/voz de riso) brasileira. Aí talvez eu tenha encontrado na cultura hallyu uma cultura pop, como se diria mundana, mas que não é escandalosa, escrachada. É uma coisa mais pura, mais bonita de se ver. Acho que talvez a minha religião tenha influenciado um pouco eu ter gostado de k-pop. (Chanli)
\end{abstract}

A possibilidade de passear entre as diferentes culturas existentes não só no Brasil, mas pelo mundo, acende nos jovens a curiosidade de conhecer e muitas vezes aderir outras realidades culturais. Este fato pode ser reforçado através da pesquisa: quando os jovens foram questionados sobre suas aspirações futuras, todos pontuaram o interesse em sair do Brasil, sendo a Coreia do Sul um dos destinos desejados. Esta diversidade cultural leva os jovens a vivenciar processos de hibridização cultural, principalmente quando sua cultura de origem já não é mais satisfatória por não suprir as expectativas sociais criadas por esta geração.

A partir da interação com a hallyu, os jovens buscam trazer para suas práticas cotidianas características que remetam a esta cultura sul-coreana. O contato com esta cultura estrangeira, na perspectiva dos jovens, vai muito além de uma simples prática de consumo. Tanto nas manifestações virtuais encontradas, ou nos diálogos realizados de forma presencial, ou nas respostas das entrevistas, é possível perceber como os jovens valorizam de alguma forma a aproximação desta cultura oriental.
Um dos pontos mais relevantes sobre a interação com a hallyu citado pelos jovens foi o fato desta reconversão cultural lhes proporcionar novas oportunidades de conhecimento e, principalmente, de relações sociais. Os jovens afirmam possuir amigos adeptos à cultura, mas não costumam manifestar muito suas apropriações da cultura hallyu. Encontrar outros adeptos à onda coreana tem se tornado uma tarefa mais fácil a partir do uso das TICs e do crescimento do movimento na região do Recife. Entretanto, de modo geral, pelo que foi percebido durante a pesquisa, os indivíduos que manifestam mais abertamente a cultura e se dispõem a participar de encontros presenciais são adolescentes, e não jovens universitários - objetos da pesquisa.

De fato, para alguns a hallyu não tem grande influência em suas práticas cotidianas, visto que, apesar de existir pontos semelhantes com a cultura mais tradicional da Coreia do Sul, não há muitas semelhanças entre a onda coreana e os costumes do local onde os jovens residem, por ser a hallyu uma cultura mercadológica, apresentando elementos mais expressivos e distintos da realidade destes jovens. Mas, apesar deste distanciamento, os jovens buscam adequar ao seu cotidiano algumas informações da onda coreana, vivenciando um processo de reconversão cultural intencional, em que buscam apropriar-se dos elementos desta cultura estrangeira a fim de formular sua identidade, que tende a ser líquida diante das muitas influências que esta geração recebe, principalmente com o uso das TICs, conforme discute de Bauman (2011). 


\section{Considerações Finais}

A partir das observações foi possível perceber que os jovens possuem similaridades em sua formação social. Como características, os jovens, com faixa etária entre 17 e 29 anos, são universitários que buscam através dos estudos novas oportunidades de crescimento e posicionamento dentro da sociedade. Parte deles possui alguma atividade remunerada, não possui crença ou religião definida, tem a tecnologia como ferramenta indispensável para suas rotinas diárias, sendo a internet sua aliada na busca por informação, posicionamento social e práticas de consumo.

Apesar de ser a cultura de origem dos jovens recifenses bastante rica, composta por tradições, festas e produções culturais que conquistam multidões, esta não aparece como atrativa a estes indivíduos que, ancorados nas TICs, buscam e encontram outras realidades culturais que lhes atrai ao seu consumo. Os jovens entrevistados confirmam tais características ao não considerarem sua cultura como referência única para sua identificação, manifestando o interesse por outras realidades culturais distintas da sua de origem.

Este interesse por outras culturas toma força com o uso da internet, que contribui para que estes jovens conheçam as mais diversas culturas existentes. Os jovens tendem a buscar e interagir com culturas que lhes permitam distinguir-se e, ao mesmo tempo, pertencerem a algum(ns) grupo(s) social(is). A interação com outras culturas não isenta a cultura de origem destes jovens, visto não ser possível ao indivíduo abstrair sua cultura de origem, principalmente quando este ainda reside no território de manifestação desta cultura local. Estes vivenciam hibridizações culturais, geralmente reconvertendo sua cultura de origem, agregando à mesma elementos da nova cultura com a qual passam a interagir.

Os jovens entrevistados, vivenciam a interação com a cultura digital e, a partir dela, descobrem outras opções para agregar à sua cultura local. Diante da gama de possibilidades de interação, alguns jovens são atraídos pela cultura transnacional que é a cultura do consumo, formulada com o propósito de estimular o consumo de bens e serviços.

A transformação da cultura em mercadoria, pela chamada indústria cultural, leva os indivíduos a verem a cultura como um bem a ser consumido. A cultura selecionada dentro das muitas opções oferecidas com a modernização social é consumida, avaliada e posteriormente mantida como elemento de consumo ou é descartada, dependendo da percepção do indivíduo que a consome. Com a evolução da sociedade, a partir da interação dos sujeitos com outras realidades, a indústria cultural tem objetificado cada vez mais a cultura, convertendo-a em um elemento a ser consumido de forma massiva, valorizando seus pontos comerciais, mais atrativos ao público.

Para autores como Adorno (2002), a indústria cultural, oriunda do capitalismo, descaracteriza a cultura ao desvalorizar sua 
função, reduzindo seu valor enquanto aumenta seu valor de mercado.

A indústria cultural condiciona os indivíduos à vivência da cultura do consumo, reforçada pela mídia, através, principalmente, da publicidade. Os sujeitos passam a consumir determinado elemento pela representatividade que enxergam neste, transformando o significado propagado pela propaganda deste em valores para sua caracterização identitária, atendendo assim aos anseios da indústria cultural.

São muitas as culturas formuladas pela indústria cultural com o propósito de comercialização de bens. Entre estas muitas culturas encontramos a hallyu, que funciona como uma cultura de consumo entre os jovens adeptos da mesma, visto ser esta apropriada pelos jovens principalmente pelo significado que percebem nos elementos que a cultura hallyu comercializa. A indústria cultural sul-coreana, materializada nas empresas de entretenimento, utiliza a hallyu para comercializar suas produções filmes, músicas, novelas e tudo mais do universo $\mathrm{K}$ que atraia público e contribua para o crescimento deste mercado. Muitos jovens brasileiros alimentam este mercado cultural, ao consumir os elementos da hallyu, a partir da interação e apropriação com esta. Os jovens observados consomem os elementos da hallyu e buscam inseri-los em suas práticas cotidianas reconvertendo as mesmas e encontrando nestas referências para sua formação identitária.
A partir da compreensão do perfil dos jovens, e do entendimento sobre o que é e como se manifesta a hallyu, foi possível perceber que os jovens observados buscam elementos distintos de sua realidade social a fim de diferenciar-se da sociedade, por não se satisfazerem com os elementos que esta oferece. Estes jovens percebem a hallyu como uma opção de referência que lhes proporciona a distinção social e, ao mesmo tempo, possibilita a estes o enquadramento em grupos sociais que lhes sejam atrativos.

Os dados analisados na perspectiva do consumo cultural e das hibridizações dos jovens entre a cultura local e a hallyu demonstram que a cultura hallyu se sobrepõe à cultura de origem dos indivíduos observados em virtude da forma como se manifesta. Utilizando principalmente as tecnologias de informação e comunicação (TICs), a cultura sul-coreana consegue alcançar os jovens recifenses e atraí-los, por meio de suas produções midiáticas, ao consumo de seus elementos - Kpop, K-movie, programas de TV e k-dramas -, estando tudo ancorado na representatividade existente na imagem dos ídolos asiáticos.

Os jovens observados têm a opção de selecionar o que desejam consumir da hallyu, visto ser o ambiente virtual seu principal espaço de apropriação cultural. A facilidade em manusear as TICs faz com que os jovens insiram estas ferramentas em suas práticas cotidianas, tornando-as essenciais para execução de suas atividades. Diante da distância geográfica e das dificuldades de 


\section{Aline Gomes Santana}

\section{Salett Tauk Santos}

compreensão do idioma coreano, os jovens utilizam a tecnologia para sanar tais dificuldades e assim se apropriar da hallyu, utilizando-a como referência para sua formação identitária.

\section{REFERENCIAS}

BAUMAN, Z. Modernidade Líquida. Brasil: Jorge Zahar. Rio de Janeiro, 2001.

BURKE, Peter. Hibridismo cultural. Coleção Aldus 18. São Leopoldo, Editora Unisinos, 2006.

CANCLINI, Néstor García. Culturas híbridas. Estratégias para entrar e sair da Modernidade. 4 ${ }^{\mathrm{a}}$. ed. $6^{\mathrm{a}}$. reimp. Editora da Universidade de São Paulo, 2013.

CUCHE, Denys. A noção de cultura nas ciências sociais. Bauru: Edusc, 1999.

CPFL, Insituto. Café filosófico: Relato de um encontro com Zygmunt Bauman por Mário Mazilli. 2017. Disponível em $<$ https://www.institutocpfl.org.br/2017/01/16/relato-de-um-

encontro-com-zygmunt-bauman-por-mario-mazzilli/> Acesso em: 31 de Out. de 2018.

KIM, Yoo Na. A jovem Coreia. São Paulo: SSUA Editora, 2008.

MARTÍN-BARBERO, Jesús. A mudança na percepção da juventude: socialidades, tecnicidades e subjetividades entre os jovens. In: BORELLI, Silvia H. S.; FREIRE FILHO, João. Culturas juvenis no século XXI. São Paulo: EDUC, 2008.

ZALIS, Pieter. A era da nostalgia. Columbia, 2016. Veja, São Paulo, ed. 2506, p. 19, 22-23, 30 nov 2016. Entrevista concedida a

Mark Lilla. 